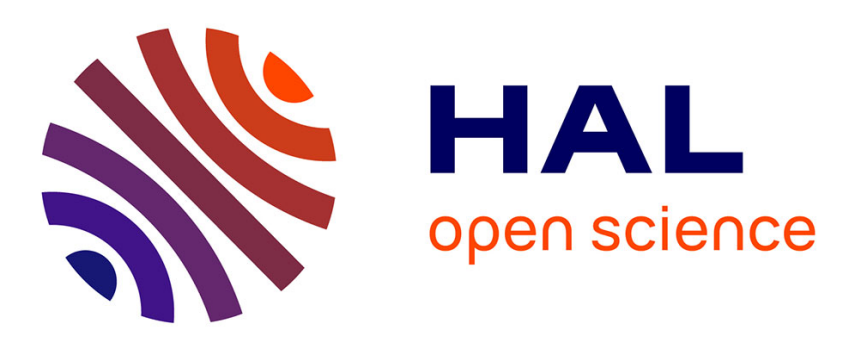

\title{
Micronized cocoa butter particles produced by a supercritical process
}

Jean-jacques Letourneau, Sébastien Vigneau, Philippe Gonus, Jacques Fages

\section{To cite this version:}

Jean-jacques Letourneau, Sébastien Vigneau, Philippe Gonus, Jacques Fages. Micronized cocoa butter particles produced by a supercritical process. Chemical Engineering and Processing: Process Intensification, 2005, 4th International Conference on Conveying and Handling of Particulate Solids, Budapest, HUNGARY, MAY 27-30, 2003, 44 (2), pp.201-207. 10.1016/j.cep.2004.03.013 · hal-01668422

\section{HAL Id: hal-01668422 https://hal.science/hal-01668422}

Submitted on 15 Mar 2018

HAL is a multi-disciplinary open access archive for the deposit and dissemination of scientific research documents, whether they are published or not. The documents may come from teaching and research institutions in France or abroad, or from public or private research centers.
L'archive ouverte pluridisciplinaire HAL, est destinée au dépôt et à la diffusion de documents scientifiques de niveau recherche, publiés ou non, émanant des établissements d'enseignement et de recherche français ou étrangers, des laboratoires publics ou privés. 


\title{
Micronized cocoa butter particles produced by a supercritical process
}

\author{
J.-J. Letourneau ${ }^{\text {a,* }}$, S. Vigneau ${ }^{\text {a }}$, P. Gonus ${ }^{\text {b }}$, J. Fages ${ }^{\text {a }}$ \\ ${ }^{a}$ Chemical Engineering Laboratory for Particulate Solids, UMR CNRS 2392, École des Mines d'Albi, Campus Jarlard, 81013 Albi, France \\ ${ }^{\mathrm{b}}$ Nestlé Product Technology Centre York, UK
}

\begin{abstract}
A process using supercritical $\mathrm{CO}_{2}$ has been developed to produce form $\mathrm{V}$ crystals of cocoa butter. In this process, solid cocoa butter is put in an autoclave in which supercritical carbon dioxide is then introduced. At high pressure, two liquid phases, one $\mathrm{CO}_{2}$-rich and one cocoa butter-rich are formed. Both of them can be sent to a depressurisation nozzle leading to particle formation in an expansion vessel. Moreover, particles can also be formed in the first autoclave undergoing slower depressurisation. Both particle populations (upstream and downstream the nozzle) have been characterised using calorimetric method (differential scanning calorimetry, DSC) and environmental scanning electron microscopy (ESEM). The polymorphism of the particles produced as well as their size and morphology show that they are potentially usable in the tempering step of the manufacturing process of chocolate.
\end{abstract}

Keywords: Cocoa butter; Supercritical; $\mathrm{CO}_{2}$

\section{Introduction}

\subsection{Polymorphism of cocoa butter and chocolate tempering}

Cocoa butter, the fat of chocolate, is responsible for the pleasant "melt in the mouth" sensation given by chocolate. It is a complex mixture of triacylglycerol (TAGs), which melting points are in the "good" range $\left(31-35^{\circ} \mathrm{C}\right)$ to give this feeling [1].

The most abundant are monounsaturated TAGs, the unsaturated fatty acid (very often oleic acid) being in the 2-position. 1-Palmitoyl-2-oleyl-3-stearoylglycerol (P-O-S), P-O-P and S-O-S account for 36-38, 14-16 and 23-28\%, respectively of the total TAGs. It is these TAGs which are mainly responsible for the behaviour of chocolate when undergoing crystallisation [2].

There are six different ways for these TAGs to arrange themselves when they crystallise. Six different polymorphs noted I - the less stable with the lowest melting point $290 \mathrm{~K}$ $\left(17^{\circ} \mathrm{C}\right)$ - to $\mathrm{VI}-$ the most stable with the highest melting point $308 \mathrm{~K}\left(35^{\circ} \mathrm{C}\right)$ - can be obtained. The relative amount of these six polymorphs will condition several features of the

\footnotetext{
* Corresponding author. Tel.: +33 563 493088; fax: +33 563493025 .

E-mail address: letourne@enstimac.fr (J.-J. Letourneau).

URL: http://wwww.enstimac.fr.
}

end product. If the wrong type of fat is present the chocolate may exhibit a white powdery surface called fat bloom which is to be avoided because of its unpleasant appearance. The most desirable form is known as form $\mathrm{V}$ (or $\beta_{2}$ ) having a melting temperature of $305-307 \mathrm{~K}\left(32-34{ }^{\circ} \mathrm{C}\right)$. The transfer to the even more stable form VI is not desirable since it might lead to fat bloom as do the less stable forms.

The processing conditions determine which polymorph is formed. To obtain predominantly form $\mathrm{V}$ a pre-crystallisation step also called tempering has been introduced in the chocolate manufacturing process. It is aimed at the formation of form $\mathrm{V}$ seed crystals which in turn will force the bulk of the remaining fat to crystallise in this stable form. Two main ways are used: (i) starting with hot liquid chocolate $318-323 \mathrm{~K}\left(45-50{ }^{\circ} \mathrm{C}\right)$ a succession of cooling to $300 \mathrm{~K}\left(27^{\circ} \mathrm{C}\right)$ in order to form both stable and unstable crystals followed by re-heating to 303-305 K (30-32 ${ }^{\circ} \mathrm{C}$ ) to melt only less stable crystals will lead to form $\mathrm{V}$ crystals which, in turn, will seed the mass of chocolate and (ii) seeding the mass of untempered chocolate by finely divided form $\mathrm{V}$ crystals of cocoa butter.

\subsection{Crystallisation with supercritical processes}

Supercritical fluid (SCF) technology presents a new and interesting route for particle formation, which avoids most of 
the drawbacks of the traditional methods of milling/crushing or liquid crystallisation. Supercritical processes are known to give micro- or even nano-particles with narrow size distribution, and may allow the control of crystal polymorphism. In addition, several other advantages inherent to these processes must be emphasised: they are single-step processes with simplified downstream processing and they are environmentally desirable since they avoid the use of organic solvents. Moreover, they allow the processing of thermolabile molecules and give high purity products [3].

Although most of the applications of supercritical particle formation are known in the pharmaceutical industry, some examples can be found with foodstuff. Cocoa butter a relatively high value product has been successfully micronised using the PGSS (particles from gas-saturated solutions) process [4]. In this paper we will investigate the production of fine cocoa butter crystals in order to use them for the seeding of chocolate.

\section{Material and methods}

\subsection{Experimental apparatus}

The experiments were carried out in a versatile pilot plant (Separex, France). A schematic diagram of the apparatus is shown in Fig. 1. Carbon dioxide is cooled and stored in a liquid $\mathrm{CO}_{2}$ storage tank (2). It can be circulated at a maximum flow of $25 \mathrm{~kg} \mathrm{~h}^{-1}$ by a membrane pump (Lewa, Germany) (3). Compressed $\mathrm{CO}_{2}$ passes then through a heat exchanger (4) and becomes supercritical. Some of the devices $(1,8,9$, 13) shown in Fig. 1 are used for other experiments such as SAS or RESS with co-solvent.

The vessel (5) (PARR Instrument, USA) is equipped with three sapphire windows (16), a magnetic stirrer (15) with a maximum torque of $1.8 \mathrm{Nm}$ and a flexible mantle heater.

The flow coming out this vessel is sprayed into the expansion vessel (7) by means of a nozzle (6) (Spraydry SK-SIY80-SKY16, orifice insert diameter: $340 \mu \mathrm{m}$, Spraying System). The powder formed is collected in a porous bag made of PTFE fibres. Then, $\mathrm{CO}_{2}$ is depressurised (10) and can either be directed to the vent or purified and recycled.

\subsection{Cocoa butter particle generation}

Pieces of solid cocoa butter are loaded in the vessel (5) equipped with a stirrer and this vessel is filled with $\mathrm{CO}_{2}$. Then, the operating temperature and the stirrer speed are fixed by the controllers. Further addition of $\mathrm{CO}_{2}$ allows reaching the operating pressure. The mixture thus obtained is stirred during a long enough period of time (at least $5 \mathrm{mn}$ at constant pressure and temperature) in order to reach the thermodynamic equilibrium. In particular if two liquid phases are present, each of them is assumed to be saturated.

The second vessel (7) is then filled with $\mathrm{CO}_{2}$ until reaching the second operating pressure. This is the expansion pressure at which the mixture is placed downstream of the nozzle. This pressure is fixed during all the experiment with a back-pressure regulator (10).

The temperature of the $\mathrm{CO}_{2}$ upstream from the stirred vessel is controlled by the heating device (4) and fixed to be the same as the temperature of the mixture in the stirred vessel.

During the experiments the valve between the two vessels is open. The saturated mixture sprayed into the expansion vessel via the nozzle, is subjected to a sudden drop in pressure, resulting in supersaturated conditions and the crystallisation of the cocoa butter. This powder is collected in the bag inside the second vessel. This process is known

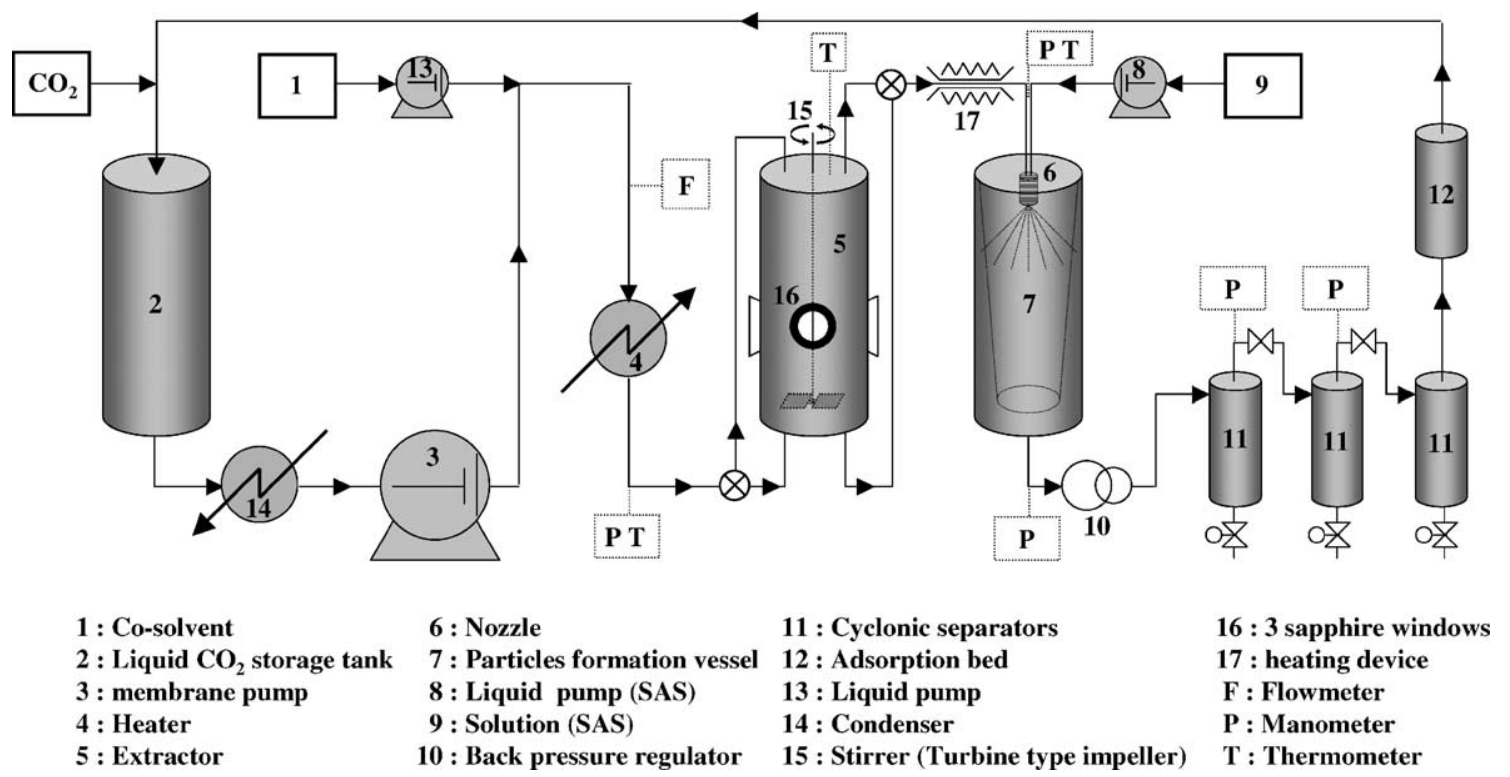

Fig. 1. Experimental set-up. 


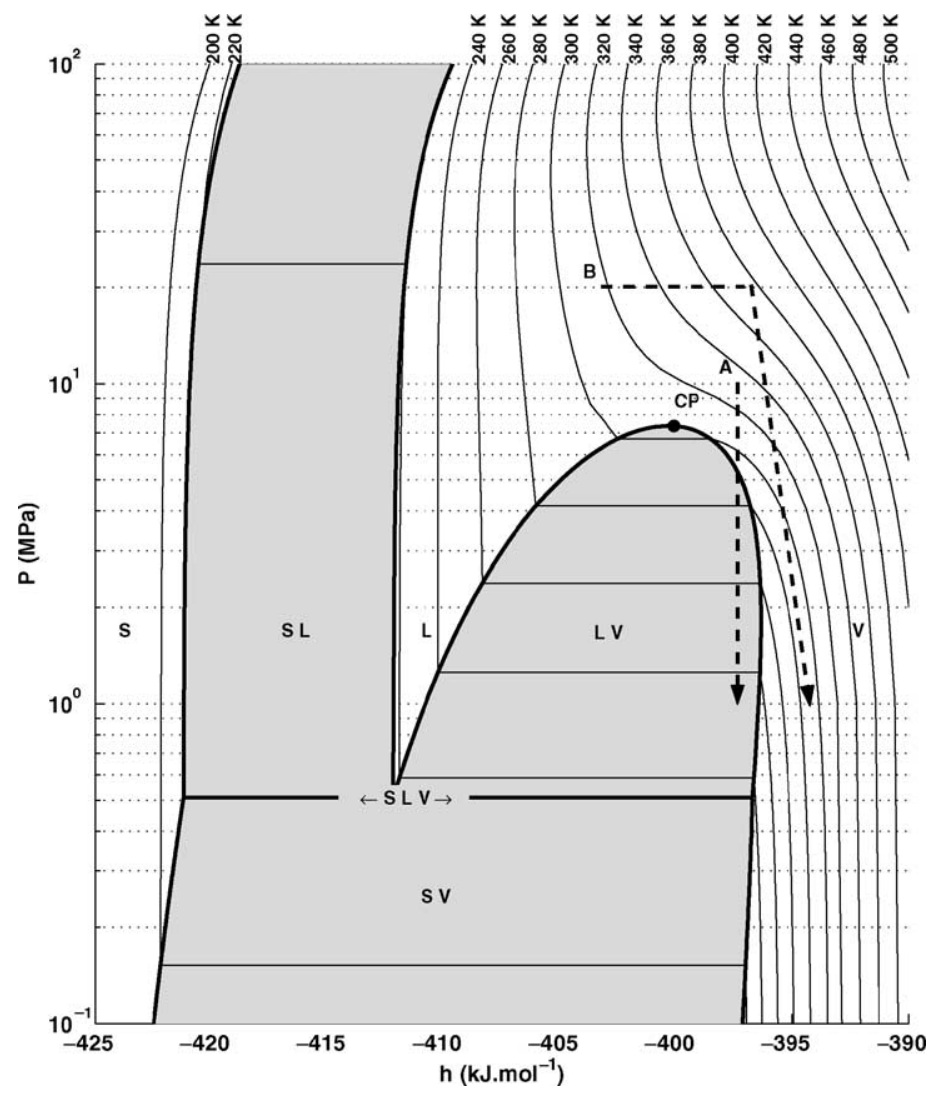

Fig. 2. Phase diagram of pure $\mathrm{CO}_{2}$ (Peng-Robinson's model [6]).

as RESS process (rapid expansion of supercritical solutions) [3].

Two major types of experiments have been achieved:

- In the first one, the first vessel is let to slowly depressurise during its emptying through the nozzle. Therefore, particles of cocoa butter can also be formed in this vessel.

- In the second, the membrane pump (3) feeds the vessel with $\mathrm{CO}_{2}$ in order to compensate the emptying via the nozzle and to maintain a constant pressure.

Another refinement in the classification of types of experiments depends on the initial load of cocoa butter. For small amounts, the mixture appears in a homogeneous single phase. On the other hand, when the initial amount increases, two phases are present.

If the temperature is too low, the solid cocoa butter formed this second phase, but with higher temperatures two fluid phases are in equilibrium: one is rich in $\mathrm{CO}_{2}$ and the other is rich in cocoa butter. Kokot et al. [5] showed that at $313 \mathrm{~K}$ and $20 \mathrm{MPa}$, the mass fractions of $\mathrm{CO}_{2}$ for these two phases are 0.44 and 0.98 . When working with two fluid phases and without stirring, the results of the experiments depend on the position of the outlet pipe of the first vessel: top or bottom. If the fluid is extracted from the top of the vessel, the cocoa butter powder is produced from the richest phase in $\mathrm{CO}_{2}$. Conversely, it is the cocoa butter rich phase which is extracted from the bottom. If the mixture is homogenised by agitation these two phases are mixed and the resulting fluid appears (as seen through the windows) to be homogeneous just like an emulsion.

The drop in pressure undergone by the mixture in the nozzle, leads also the temperature to fall and crystals of $\mathrm{CO}_{2}$ may appear $\left(\mathrm{CO}_{2}\right.$ triple point: $\left.T=216.6 \mathrm{~K}, P=0.52 \mathrm{MPa}\right)$. To prevent this solid $\mathrm{CO}_{2}$ formation, the pressure $P_{7}$ in the expansion vessel must be kept beyond the triple point pressure. But this does not always prevent the $\mathrm{CO}_{2}$ liquefaction if the temperature upstream the nozzle is not high enough. As an example shown in Fig. 2 (path A), the final temperature of pure $\mathrm{CO}_{2}$ at $T=333 \mathrm{~K}$ submit to an isenthalpic depressurization from $P=10$ to $1 \mathrm{MPa}$ is $T=233 \mathrm{~K}$, which is a point within the boundary of the liquid-vapour region. The presence of two phases-liquid and gas-around the particles in formation could change the growth of the crystals and therefore their final morphology. The heating device (17) is used to prevent the temperature $T_{7}$ in the expansion vessel to be lower than the dew temperature of pure $\mathrm{CO}_{2}$ at $P_{7}$. The theoretical path for the experiment \#3 of Table 1 is shown in Fig. 2 (path B). For this experiment boiling water has been used in the heating device and the final temperature of the mixture at $T=373 \mathrm{~K}$ submit to a depressurization from $P=20$ to $1 \mathrm{MPa}$ is $T=288 \mathrm{~K}$. As it can be seen this depressurization is almost isenthalpic.

The flowrate of $\mathrm{CO}_{2}$ is adapted to fit with the operating conditions. It mainly depends on the characteristics of the 
Table 1

Experimental operating conditions

\begin{tabular}{|c|c|c|c|c|c|c|c|c|c|}
\hline Experiment number & Series & Diam. (mm) & $M_{0}(\mathrm{~g})$ & $V_{5}\left(\mathrm{~cm}^{3}\right)$ & $P_{5}(\mathrm{MPa})$ & $T_{5}(\mathrm{~K})$ & $P_{7}(\mathrm{MPa})$ & $T_{7}(\mathrm{~K})$ & Duration (min) \\
\hline 1 & E-I & 0.34 & 20.8 & 2000 & 20 & 313 & 0.6 & 288 & 23 \\
\hline 2 & E-I & 0.34 & 30.6 & 2000 & 25 & 373 & 0.3 & 288 & 28 \\
\hline 3 & E-I & 0.41 & 18.6 & 2000 & 20 & 318 & 1 & 288 & 22 \\
\hline 4 & E-I & 0.41 & 36 & 2000 & 20 & 323 & 0.1 & 288 & 21 \\
\hline 5 & E-I & 0.41 & 19.9 & 2000 & 30 & 313 & 0.9 & 288 & 21 \\
\hline 6 & E-II & 0.41 & 20.6 & 2000 & 30 & 303 & 0.1 & 291 & 10 \\
\hline 7 & E-II & 1.50 & 20.2 & 2000 & 25 & 303 & 0.1 & 293 & 6 \\
\hline 8 & E-III & 0.41 & 19.9 & 2000 & 30 & 313 & 0.1 & 289 & 4 \\
\hline 9 & E-III & 1.50 & 102.3 & 2000 & 31 & 298 & 0.1 & 292 & 3 \\
\hline 10 & E-IV & 0.34 & 99.7 & 2000 & 20 & 293 & 0.7 & 291 & 7 \\
\hline 11 & E-IV & 0.34 & 106.4 & 2000 & 27 & 305 & 0.4 & 288 & 24 \\
\hline 12 & E-IV & 0.41 & 100.6 & 2000 & 20 & 313 & 0.2 & 288 & 14 \\
\hline 13 & E-IV & 0.41 & 94.4 & 2000 & 32 & 313 & 0.3 & 288 & 15 \\
\hline 14 & E-V & 0.34 & 128 & 1200 & 20 & 303 & 4 & 283 & 5 \\
\hline 15 & E-V & 0.34 & 135 & 1200 & 25 & 308 & 2 & 283 & 5 \\
\hline
\end{tabular}

Diam.: diameter of the nozzle orifice; $M_{0}$ : initial mass of cocoa butter; $V_{5}, P_{5}, T_{5}$ : volume, pressure and temperature of the tank (5), respectively; $P_{7}$, $T_{7}$ : pressure and temperature of the tank (7), respectively.

nozzle and on the pressure difference $P_{5}-P_{7}$ between the two vessels. A typical flowrate value for the experiences listed in Table 1 is about $20 \mathrm{~kg} \mathrm{~h}^{-1}$.

\subsection{Powder characterisation}

Differential scanning calorimetry (DSC) has been used to characterise the samples in a DSC-7 Perkin-Elmer. The DSC patterns of the samples $(2-5 \mathrm{mg})$ were obtained between 283 and $323 \mathrm{~K}$ at a heating rate of $5 \mathrm{~K} \mathrm{~min}^{-1}$ in a $\mathrm{N}_{2}$ gas stream.

The picture presented in Figs. 4 and 5 have been made with an Environmental Scanning Electron Microscope (XL30 ESEM FEG, FEI Philips, The Netherlands).

In order to use these powders for chocolate seeding, a characterisation of their mechanical and rheological properties is needed and this will be done in future work.

\subsection{Tempering experiments}

Chocolate tempering experiments were carried out by seeding with various type of cocoa butter powder. The degree of pre-crystallisation (temper) was measured using a computerised tempermeter (Exotherm 7400 from Systech Analytics). This measurement is basically a cooling curve where the change in temperature is measured against the time. The chocolate sample is taken at processing temperature in a special container and placed in the instrument cell at $281 \mathrm{~K}\left(8^{\circ} \mathrm{C}\right)$. In a typical tempering curve, the exothermic process of crystallisation generates an inflexion point. The slope at this point is used to determine whether the chocolate is under-, well- or over-tempered. Usually a well-tempered curve shows a horizontal plateau. More details on tempering curve measurements can be found in Bolliger et al. [7].

The process of cocoa butter seeding is usually carried out at $303 \mathrm{~K}\left(30^{\circ} \mathrm{C}\right)$ where a mass fraction of $0.5-2 \%$ of ordinary cocoa butter seeds is mixed with the melted chocolate.

\section{Results and discussion}

\subsection{Particle formation experiments}

The first series of experiments (E-I) was done with small amounts of cocoa butter (single-phase system) and with continuous feeding in $\mathrm{CO}_{2}$. The second series (E-II) was done without feeding and top extraction: particles were collected in both vessels. The third series (E-III) was done without feeding and bottom extraction: particles were collected in both vessels. The fourth series (E-IV) was done with larger amounts of cocoa butter, continuous feeding and bottom extraction. The fifth and last series of experiments (E-V) was done with larger amounts of cocoa butter and homogeneous mixing.

Two typical experiments have been selected for discussion: the experiment \#5 which belongs to the first series (rapid expansion of a single-phase mixture with continuous feeding in $\mathrm{CO}_{2}$ ) and the experiment \#15 of the fifth series (rapid expansion of a two-phase stirred mixture).

In Fig. 3, the DSC patterns for the original cocoa butter and for experiments 5 and 15 are shown. Original cocoa butter shows a peak at $T=307.1 \mathrm{~K}$, an end-set point at $T=309.6 \mathrm{~K}$ and a melting enthalpy of $\Delta h^{\text {fus }}=131 \mathrm{~J} \mathrm{~g}^{-1}$, which are characteristics values for form VI crystals.

The powder obtained in experiment 15 was collected in the bag of the expansion vessel. Its characteristics are: $T_{\text {peak }}$ $=304 \mathrm{~K}, T_{\text {end-set }}=306.3 \mathrm{~K}$ and $\Delta h^{\text {fus }}=120.3 \mathrm{Jg}^{-1}$. This form $\mathrm{V}$ powder was white, light, with regular individual particles and was free-flowing. Nearly all experiments were achieved with the following conditions: nozzle orifice diameter $\leq 340 \mu \mathrm{m}, 298 \leq T_{5} \leq 308 \mathrm{~K}, P_{5} \geq 20 \mathrm{MPa}$ and $0.5 \leq P_{7} \leq 4 \mathrm{MPa}$ led to the same kind of form $\mathrm{V}$ powder collected in the expansion vessel (7). A typical example of this kind of particle is shown on Fig. 4. It is made of an agglomeration of smaller particles. 


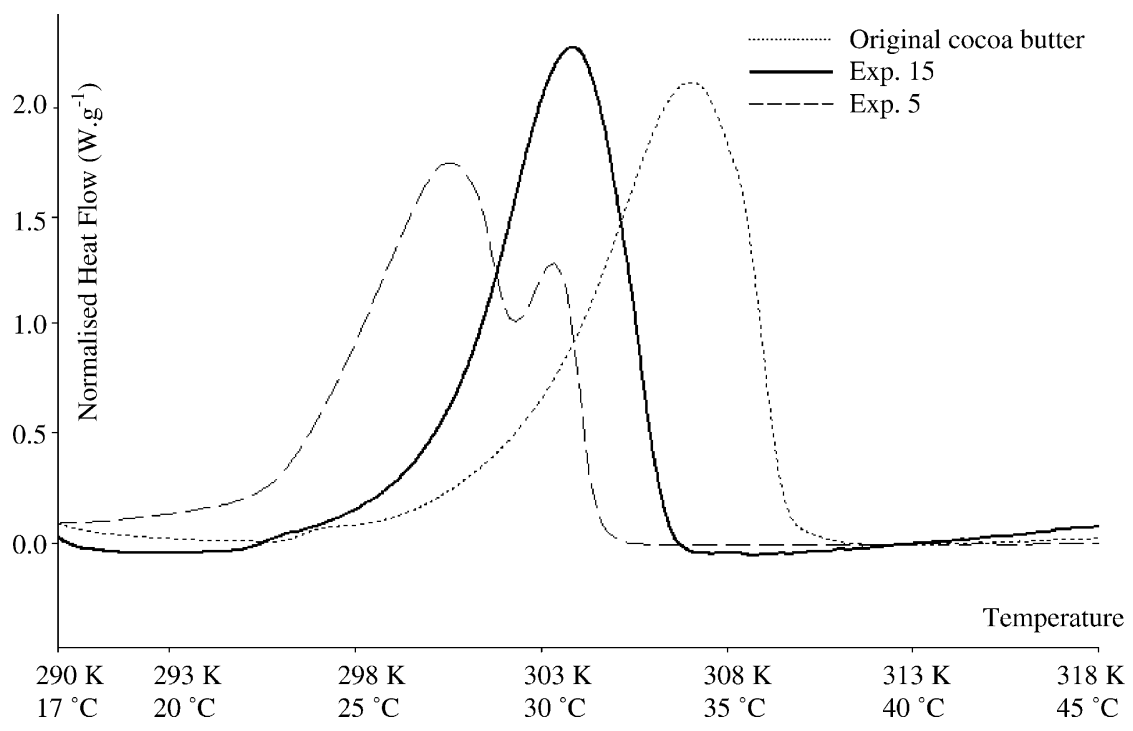

Fig. 3. Typical DSC curves.

The powder obtained in experiment 5 was collected in the vessel (5) and has the following characteristics: $T_{\text {peak }}$ $=300.5 \mathrm{~K}, T_{\text {end-set }}=302.5 \mathrm{~K}$ for the first peak and: $T_{\text {peak }}$ $=303.7 \mathrm{~K}, T_{\text {end-set }}=305.0 \mathrm{~K}$ for the second peak. All the particles obtained in this vessel are made of a mixture of both forms IV and V. The faster the drop in pressure in this vessel, the larger the quantity of form $\mathrm{V}$ powder obtained. A typical example of this kind of particle is shown in Fig. 5. This

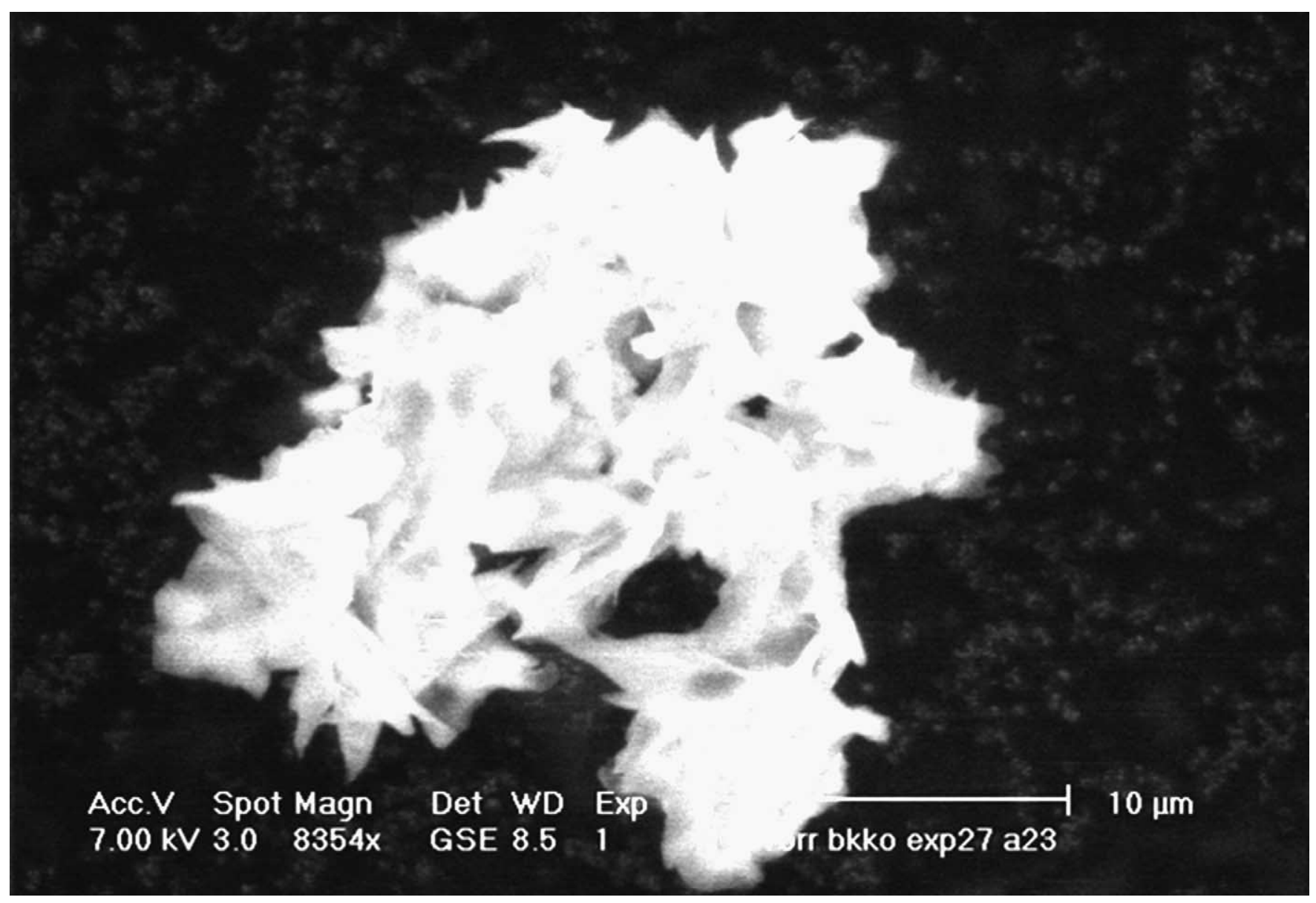

Fig. 4. ESEM picture of a cocoa butter particle obtained with experiment \#15. 


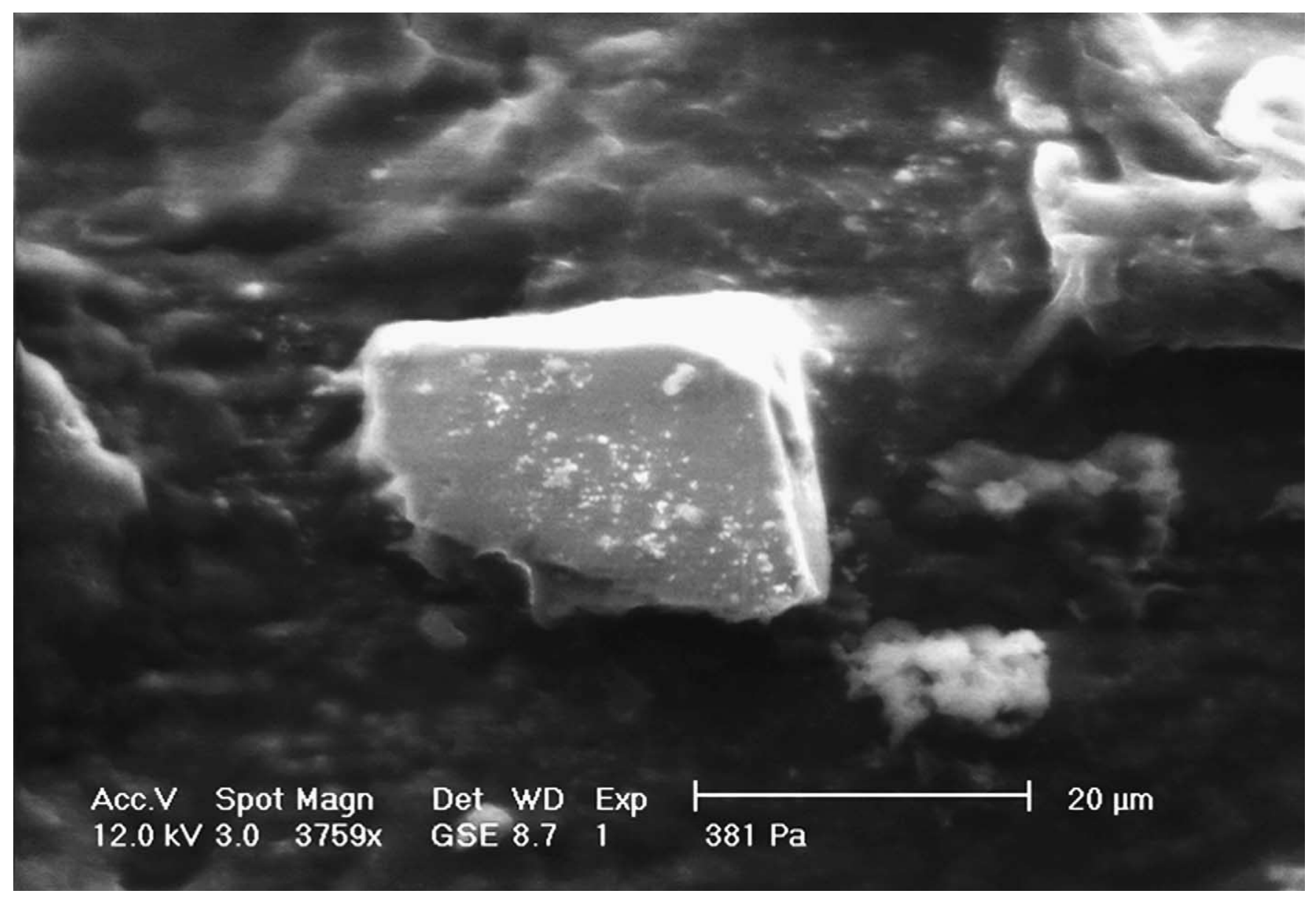

Fig. 5. ESEM picture of a cocoa butter particle obtained with experiment \#5.

powder is generally white, extremely light and sometimes pieces of original yellow cocoa butter can be found among the particles.

\subsection{Seeding of chocolate}

The cocoa butter powder obtained by supercritical process was able to seed using the following conditions.

At $306 \mathrm{~K}\left(33^{\circ} \mathrm{C}\right)$ and above, the seeding produced an under-tempered chocolate; at $304 \mathrm{~K}\left(31^{\circ} \mathrm{C}\right)$ and below, the chocolate was quickly over-tempered. However, at $305 \mathrm{~K}$ $\left(32{ }^{\circ} \mathrm{C}\right)$, good tempering conditions were obtained with less than $0.3 \%$ of cocoa butter seeds. This is at least $2{ }^{\circ} \mathrm{C}$ higher than common seeding and several degrees higher than most industrial tempering step. Therefore, the chocolate is very much thinner.

The powder samples described in series E-I and E-IV (obtained with the smallest nozzle) gave the best results. The seeding was carried out at $305 \mathrm{~K}\left(32^{\circ} \mathrm{C}\right)$ with a mass fraction of $0.1-0.2 \%$ and produced a well-tempered chocolate. At this high temperature, the stirrer velocity is a critical point as an excess of mechanical energy could melt the seeds, but this has to be tested using an industrial scale tempering machine (batch or continuous).

\section{Perspectives and conclusion}

The best cocoa powders in terms of appearance, DSC, reproducibility and shelf-stability are those of the E-V series. They have not been tested yet to seed chocolate and this will be part of a future work.

High shear stresses are known to favour the most stable forms of the cocoa butter. The same phenomenon is probably also appearing in the supercritical generation of cocoa butter particles: when the particles are generated in the expansion vessel with a huge drop in pressure through a small nozzle, they are exclusively made of form $\mathrm{V}$ - when generated in the first vessel with a slow drop in pressure form IV is present and even predominant. This is a track for further studies.

A major interest in using this new process [8] is the value of the temperature at which seeding can be done with the cocoa butter particles "supercritically" generated. At $305 \mathrm{~K}$ the chocolate is less viscous, this is advantageous in term of flowability and energy consumption. An additional advantage lies in the fact that the time needed to obtain a well-tempered chocolate is shorter (about $5 \mathrm{~min}$ ). Moreover, the overall quantity of seeds to temper the chocolate is very small. Therefore, a scaling-up of this process to an industrial scale appears feasible. 


\section{References}

[1] S.T. Beckett, The Science of Chocolate, RSC Paperbacks, 2000.

[2] M. Lipp, E. Anklam, Review of cocoa butter and alternative fats for use in chocolate. Part A. Compositional data, Food chem. 62 (1998) 73-97.

[3] J. Fages, H. Lochard, E. Rodier, J.-J. Letourneau, M. Sauceau, La Génération de Solides Divisés par Fluides Supercritiques, Can. J. Chem. Eng. 81 (2003) 161-175.

[4] Z. Knez, E. Weidner, Precipitation of solid with dense gases, in: A. Bertucco, G. Vetter (Eds.), High Pressure Process Technology: Fundamentals and Applications, Elsevier, 2001, pp. 587-611.
[5] K. Kokot, Z. Knez, D. Bauman, S-L-G (solid-liquid-gas) phase transition of cocoa butter in supercritical $\mathrm{CO}_{2}$, Acta Alimentaria 28 (1999) 197-208.

[6] D.-Y. Peng, D. Robinson, A new two-constant equation of state, Ind Eng. Chem. Fundam. 15 (1976) 59-64.

[7] S. Bolliger, B. Breitschuh, M. Stranzinger, T. Wagner, E.J. Windhab, Comparison of precrystallization of chocolate, J. Food Eng. 35 (1998) 281-297.

[8] J. Fages, J.-J. Letourneau, Procédé de production de particules, French Patent FR 2847486 (2002). 